\title{
ANÁLISE MULTICRITERIAL EM ESTRATÉGIA DE OPERAÇÕES: ESTUDO DE CASO COM COMPRADORES DE ARROZ DE SEIS REDES SUPERMERCADISTAS
}

\section{MULTICRITERIAL ANALYSIS IN OPERATION STRATEGY: CASE STUDY WITH RICE PURCHASERS OF SIX RETAILER FIRMS}

\author{
Marcelo Fernandes Pacheco Dias* E-mail: marcelo.fernandes@ufrgs.br \\ Jaime Evaldo Fensterseifer**E-mail: jfenster@ea.ufrgs.br \\ Miguel Afonso Sellitto**E-mail: sellitto@unisinos.br \\ *Universidade Federal do Rio Grande do Sul \\ **Universidade de Caxias do Sul, UCS, Caxias do Sul, RS \\ ***Universidade do Vale do Rio dos Sinos - UNISINOS, São Leopoldo, RS
}

\begin{abstract}
Resumo: O objetivo deste artigo foi apresentar um estudo de caso múltiplo que mensurou a prioridade dada por seis empresas compradoras de arroz aos critérios de competição observados no setor. O estudo de caso múltiplo foi feito em seis dos maiores supermercados com operações em Santa Catarina e Rio Grande do Sul. A competição no setor foi descrita por uma estrutura em forma de árvore. A primeira camada da estrutura incluiu os critérios preço, qualidade, variedade, imagem, desempenho de entrega e assistência ao comprador. Para a priorização, foi distribuída importância relativa entre os critérios de competição da estrutura, com base no método AHP de apoio à decisão multicriterial. A competição por qualidade foi a mais valorizada por cinco das seis empresas. A sexta valorizou mais a variedade. Comparações internas foram feitas entre os resultados da segunda camada da estrutura de competição.
\end{abstract}

Palavras-chave: Estratégia de Operações, Critérios Competitivos, Decisão Multicriterial, AHP em Estratégia, Preferências de Compradores.

Abstract: This article aims at presenting a multiple case study in which we measured the prioritization given to competitive factors by six companies that buy rice products for retailing. The multiple case study took place in six large self-service food agents that operate in Santa Catarina and Rio Grande do Sul. The competition in the industry was described by a tree-like structure, which first layer includes: price, quality, variety, image, deliver and services as competitive factors. For prioritizing, we distributed relative importance between factors, with the aid of the AHP method of multicriteria decision support. Quality was prioritized in five companies. The other one prioritized variety. Internal comparisons were made with the results from second layer of the structure.

Keywords: Operations Strategy; Competitive Criteria; Multicriteria Decision; AHP in Strategy; Purchasers Preference.

\section{INTRODUÇÃO}

O setor agroindustrial arrozeiro brasileiro tem se caracterizado por fracos resultados econômicos como conseqüência da baixa competitividade das empresas. 
O setor acredita que isto se dê pela baixa diferenciação do produto, como conseqüência da prioridade dada à competição por baixo preço. No entanto, as empresas do setor operam com compradores que valorizam vários critérios competitivos, não só o preço, o que oportuniza a diversificação estratégica (DIAS e FENSTERSEIFER, 2005). Entre estes compradores, destacam-se os supermercados e hipermercados. No Brasil, os dez maiores supermercados participam com $45 \%$ do faturamento do setor de auto-serviço de alimentos (SUPERHIPER, 2006).

O alinhamento da estratégia de operações com a estratégia de negócio pode contribuir para a melhoria da competitividade da indústria arrozeira. Para tanto, é preciso identificar as prioridades dadas por compradores aos múltiplos critérios competitivos. Estes formam um conjunto consistente que a empresa deve valorizar para competir com sucesso no mercado. Tal prática aprimora as decisões ligadas à área de operações na busca de vantagens competitivas (PAIVA et al., 2004).

O objetivo deste artigo é propor e testar um método para a mensuração das prioridades ou graus de importância de critérios competitivos valorizados por compradores institucionais na decisão de compra de arroz. A questão de pesquisa foi: como mensurar as prioridades de critérios competitivos dadas por compradores de arroz? O método de pesquisa foi o estudo de caso múltiplo: três supermercados em Santa Catarina (SC) e três no Rio Grande do Sul (RS). A priorização foi feita por distribuição de importância relativa (cem pontos percentuais são distribuídos entre os critérios competitivos), com a utilização do método AHP (Analytic Hierarchy Process) de apoio à decisão multicriterial. Como as empresas não formam uma amostra representativa da indústria, não é válido estender as conclusões para o setor. As principais contribuições do artigo são os resultados específicos dos seis casos e o método, que pode ser replicado em outras empresas na mesma indústria.

O restante está organizado em: revisão bibliográfica sobre estratégia de operações e AHP; descrição da pesquisa; discussão de resultados; implicação da pesquisa em gestão estratégica de operações; e considerações finais. 


\section{ESTRATÉGIA DE OPERAÇÕES E FOCO ESTRATÉGICO}

Várias definições surgem na literatura para estratégia de operações. Wheelwright (1984) define estratégia de operações como um padrão de decisões ao longo do tempo, que irá colaborar para a construção de uma vantagem competitiva. Uma consideração recorrente é a menção ao princípio básico colocado originalmente por Skinner (1969): atributos e decisões em operações funcionando como elo de ligação com a estratégia de negócio da empresa.

Os principais elementos que definem o conteúdo de uma estratégia de operações são os critérios competitivos relacionados com a estratégia competitiva ou de negócio da empresa e as categorias ou áreas de decisão, relacionadas com as políticas de operação adotadas pela empresa. As categorias de decisão são: estruturais (capacidade, instalações, tecnologia e integração vertical), que se caracterizam por serem mais onerosas, de longo prazo e de difícil reversão; e infraestruturais (organização da produção, força de trabalho, gerência da qualidade, relações com fornecedores e planejamento e controle da produção), que se caracterizam por serem decisões menos onerosas, de mais curto prazo que as estruturais e de mais fácil reversão (WHEELWRIGTH, 1984). Sellitto e Walter (2006) classificam as decisões em basais e incrementais. As primeiras são tomadas poucas vezes na história do negócio, mudam características importantes de competitividade e condicionam e delimitam as segundas; estas são tomadas com maior freqüência e seus efeitos geralmente se somam aos de outras decisões, corrigindo-as e ajustando o curso das ações. As políticas adotadas em relação às categorias de decisões constituem a estratégia de operações.

A obtenção de vantagens competitivas se relaciona a atributos dos produtos ou dos serviços da empresa. Dentre estes, alguns interessam ao comprador, tais como, preço, qualidade do produto e variedade. Outros ao produtor, tais como custo, produtividade ou rapidez de fabricação (CONTADOR, 1995). Para diferenciá-los, o autor utilizou os termos campos e armas da competição. Campos são os atributos que interessam ao comprador e armas são os meios ou capacitações necessárias para alcançar vantagem competitiva nos campos. Ao formular a estratégia, a empresa deve ter a clareza sobre quais atributos os compradores valorizam, e quais são as capacitações que criam e dão suporte aos mesmos. 
Diversos autores mencionam critérios competitivos em estratégia de operações (HILL, 1994; WHEELWRIGHT, 1984; FINE e HAX, 1985; SLACK, 2002; PLATTS e GREGORY; 1992). Para Slack (2002), os principais são: custo, qualidade, flexibilidade, confiabilidade e velocidade de entrega. Paiva et al. (2004) acrescentaram "inovatividade": a capacidade de inovar na indústria. Davis et al. (2001) apontam serviços associados a produtos de base tecnológica. Hill (1994) separa os critérios em qualificadores, aqueles que permitem que uma empresa entre na disputa, e ganhadores de pedidos, aqueles que, entre os participantes, decidem a disputa. Slack (2002) desdobra os critérios competitivos em aspectos internos e externos. Os externos são percebidos pelos clientes; os internos são as capacitações que a empresa desenvolve para ter desempenho nos aspectos externos, em correspondência à terminologia de campos e armas de competição de Contador (1995). Consideram-se os aspectos externos (campos da competição) na fase de identificação dos critérios e os internos (armas da competição) na fase de formulação das estratégias de operações.

Entre critérios competitivos, geralmente há a necessidade de soluções de compromisso, os trade-offs: para obter vantagem em um critério de maior grau de importância, a empresa abre mão de outro, de menor importância. Os trade-offs impedem a empresa de competir em todos os campos simultaneamente. Por exemplo, se existe um trade-off entre custo e flexibilidade, um aumento neste causará um impacto negativo naquele. Ademais, os trade-offs não são estáticos; eles mudam com o tempo e com as circunstâncias (CORBETT e WASSENHOVE, 1993). Para ser competitiva, a empresa deve focalizar as operações em um ou poucos critérios competitivos, ou seja, definir prioridades competitivas.

A distinção entre as estratégias de operações adotadas por empresas reside no peso atribuído aos critérios competitivos e na forma como são buscados no dia-adia das operações (PAIVA et al., 2004). O peso de cada critério competitivo deve refletir seu grau de importância no segmento de mercado em que a empresa atua.

\subsection{Multicriterialidade em estratégia de operação}

Multicritérios estão presentes em situações complexas ou de incerteza, tais como as que ocorrem em estratégia de operação. Um problema multicriterial pode 
nascer de visões controversas e conflituosas de grupos com diferentes interesses sobre um tema. Neste tipo de problema, o decisor escolhe alternativas que abrem mão de objetivos menos valiosos em prol dos mais valiosos, segundo multicritérios de avaliação. A forma canônica do problema é um enunciado e um conjunto de alternativas $\mathbf{A}$, julgadas sob um conjunto de critérios $\mathbf{C}$, cada critério $C_{i}$ influenciando o enunciado do problema com um peso $w_{i}$. Dados $\mathbf{A}$ e $\mathbf{C}$, é preciso um método para encontrar os $w_{i}$ (KEENEY e RAIFFA, 1976; CHIOU e TZENG, 2002).

Dentre os métodos existentes, o processo de análise hierárquica AHP (Analytic Hierarchy Process) é, possivelmente, o mais conhecido e mais usado (SALOMON e MONTEVECHI, apud SALOMON, 2002). O método é abundantemente exemplificado na literatura (PARTOVI et al., 2002; LIU e HAI, 2005) e sua fundamentação e procedimentos são descritos em Saaty (1991) e Forman e Selly (2001).

Os multicritérios são julgados por comparações pareadas. Para $n$ critérios, são requeridas $n .(n-1) / 2$ comparações entre os critérios $a_{i}$ e $a_{j}, \forall i, j$, que formam uma matriz de preferências $C_{i, j}(n \times n)$. A comparação é feita respondendo-se a questões. Ao influenciar o nível acima, o critério $a_{i}$ é mais importante, menos importante ou igual em importância ao critério $a_{j}, \forall i, j$ ? Para os $a_{i, j}$ não-equivalentes, e dado que $a_{i}$ é mais importante do que $a_{j}, a_{i}$ é: (i) um pouco mais importante do que $a_{j}$ ? (ii) mais importante do que $a_{j}$ ? (iii) muito mais importante do que $a_{j}$ ? ou (iv) absolutamente mais importante do que $a_{j}$ ? A matriz de preferências segue a Tabela 1. Valores intermediários resolvem situações intermediárias, quando duas alternativas são muito parecidas (SAATY, 1991).

Tabela 1- Opções de preferência com base em comparação pareada

\begin{tabular}{cccc}
\hline se $a_{i}$ em relação $a$ a $a_{j}=$ & Então $c_{i j}=$ & Se $a_{i}$ em relação $a a_{j}=$ & então $c_{i j}=$ \\
\hline igual & 1 & Igual & 1 \\
um pouco mais importante & 3 & um pouco menos importante & $1 / 3$ \\
mais importante & 5 & menos importante & $1 / 5$ \\
muito mais importante & 7 & muito menos importante & $1 / 7$ \\
absolutamente mais & 9 & absolutamente menos & $1 / 9$ \\
importante & & importante &
\end{tabular}

Fonte: Saaty (1991)

Por fim, calcula-se a importância relativa dos critérios pelos autovetores com máximos autovalores da matriz. Os componentes do autovetor são as prioridades dos critérios e o autovalor dá a medida de consistência do julgamento, dentro das 
bases propostas pelo método. Se A for a matriz de comparações, deve-se encontrar o vetor de prioridades $\mathbf{w}$, tal que satisfaça a equação 1. A razão de consistência $C R$ é calculada pela equação 2 .

$$
\begin{gathered}
A . w=\lambda_{\max } \cdot \mathrm{w}(\text { equação } 1) ; \\
C R=\left[\lambda_{\max }-n\right] /[I R .(n-1)](\text { equação } 2) ;
\end{gathered}
$$

na qual: (i) $n$ é o número de critérios; (ii) $\lambda_{\max } \leq n$ é o maior autovalor; e (ii) IR é o índice randômico médio, obtido por simulações com amostras de matrizes ndimensionais. A CR é a probabilidade que o resultado tenha sido alcançado aleatoriamente e que não constitua uma estrutura de preferências originada de um julgamento racional. Saaty (1991) sugere arbitrariamente que se aceite $C R<0,10$, do contrário recomenda a identificação e reformulação dos julgamentos que contribuíram para a inconsistência. Hogart (1988), no entanto, alerta que se deve contar com certa inconsistência no modelo mental e em julgamentos de decisores, o que pode ser apreendido pela $C R$.

Métodos multicriteriais em análises estratégicas têm surgido na literatura. Entre muitas outras obras, citam-se algumas, mais relacionadas à presente pesquisa. Até quanto se pesquisou, a obra mais antiga encontrada envolvendo o método AHP em análise estratégica foram propostas por Wind e Saaty (1980) e Wind e Douglas (1981). Os autores usaram o método em análise de mercado e portfolio. Lu et al. (1994) combinaram o AHP com outros métodos para priorizar estratégias em marketing. Partovi et al. (1993) usaram o método para estabelecer prioridades em gerenciamento de operações ligadas à seleção de fornecedores, localização de instalações e escolha da tecnologia. Liberatore (1987) escolheu projetos e alocou recursos segundo uma estratégia de projeto. Abdi e Labib (2003) selecionaram tecnologia de manufatura segundo objetivos estratégicos de produção. Bertolini e Bevilacqua (2006) combinaram métodos para uso em estratégia de manutenção. Rangone (1996) e Bititci et al. (2001) usaram o método para mensuração de desempenho em operações industriais. Masella e Rangone (2000) usaram o AHP para seleção de fornecedores. Por fim, Kurtilla et al. (2000) associaram o AHP à matriz SWOT para análise estratégica em silvicultura. 
O AHP tem sofrido críticas. Dyer (1990a; 1990b) apontou alterações que podem acontecer na ordenação quando alternativas são adicionadas. Saaty (1990) e Harker e Vargas (1990) apresentaram réplica. Sellitto (2005) apontou o mesmo fenômeno quando um critério de decisão foi retirado da análise. Machado et al. (2003) resenharam e comentam as críticas. Gomes et al. (2004) e Liu e Hai (2005) apresentaram alternativas de modificação do método. Saaty (2006) voltou ao assunto, dizendo que a avaliação de alternativas em relação a critérios pode ser relativa ou absoluta. $\mathrm{Na}$ avaliação relativa, compara-se cada alternativa com todas as demais. Na avaliação absoluta, compara-se com uma alternativa ideal. $\mathrm{O}$ autor pontua que, em comparação relativa, as alternativas tornam-se estruturalmente dependentes: os valores obtidos para uma alternativa variam com o número e a qualidade das demais alternativas, incorporando ao AHP os fenômenos que podem ocorrer na entrada e saída de critérios.

\section{A PESQUISA}

O objetivo de pesquisa foi mensurar a prioridade ou grau de importância de critérios de decisão ou preferências de estrategistas compradores de seis supermercados, produzindo um vetor de preferências para cada operação. A principal contribuição do artigo não é um vetor geral de preferências estratégicas para a operação arrozeira, mas um método para obter o vetor em cada caso. $\mathrm{O}$ resultado específico é válido apenas para a empresa em que foi achado

Para explicar o Desempenho Estratégico na Comercialização de Arroz, foi utilizada uma estrutura apresentada em Dias e Fensterseifer (2005). A estrutura decompõe o termo em dimensões hierárquicas que o desdobram e explicam. Calcularam-se importâncias relativas das dimensões, gerando uma combinação linear para as preferências de compra. Alternativas de decisão são planos de operação que, caso compitam por recursos limitados, tornam a combinação linear a função-objetivo de um problema de otimização. Chega-se à forma canônica do problema de decisão multicriterial: um enunciado intangível e complexo, com incertezas e controvérsias, o desempenho estratégico; os critérios e subcritérios, as dimensões desdobradas; e as alternativas e planos de operações a julgar. 
A questão de pesquisa foi: como mensurar as prioridades de critérios competitivos dadas por compradores de arroz? Questões como remetem ao método do estudo de caso, que pode ser exploratório, descritivo ou explicativo (YIN, 2001). O método pode contribuir para uma teoria de cinco modos: (i) oferecer, para posteriores estudos, uma descrição profunda e específica de um objeto; (ii) interpretar eventuais regularidades como evidências de postulados teóricos; (iii) criar uma situação para testar uma idéia; (iv) sondar plausivelmente uma teoria proposta pelo terceiro modo; e (v) o caso crucial, que apóia ou refuta a teoria (ECKSTEIN, 1975, apud ROESCH, 1999). Um risco do estudo de caso apontado por Eisenhardt (1989) é que se chegue a hipóteses idiossincráticas ou teorias não-generalizáveis, que representem visões parciais, geralmente oriundas das crenças de pesquisadores ou particularidades do objeto. Para minimizar este risco, a autora sugere múltiplos casos, até para construção indutiva de teorias fundamentadas (grounded theory). Os casos são repetidos até que os avanços nos achados sejam marginais, apontando que pode-se então enunciar uma hipótese a ser verificada em pesquisas do tipo survey.

Entende-se que este foi um estudo de caso exploratório: a aplicação inicial de uma idéia; e que a contribuição é do terceiro tipo: uma situação construída para o teste da idéia, que será refinada por repetição e aprendizado. As empresas estudadas foram os supermercados Giassi, Angeloni e Wal-Mart, em Santa Catarina, e Big Wal-Mart, Zaffari e Unidasul, no RS. A principal técnica de pesquisa foi a entrevista semi-estruturada. Após conhecer os objetivos da pesquisa, os respondentes foram apresentados à estrutura do Quadro 1, que organiza a competição em compra de arroz. 
Quadro 1 - Estrutura de preferências em decisões de compra de arroz

\begin{tabular}{|c|c|c|}
\hline $\begin{array}{l}\text { Campos da } \\
\text { competição }\end{array}$ & $\begin{array}{l}\text { Dimensões } \\
\text { competitivas }\end{array}$ & Critérios competitivos \\
\hline \multirow[t]{3}{*}{ Preço } & \multirow[t]{2}{*}{ Preço } & Preço unitário cobrado \\
\hline & & \begin{tabular}{|l|} 
Regularidade do preço ao longo do ano \\
\end{tabular} \\
\hline & Prazo de pagamento & Prazo de pagamento habitualmente concedido \\
\hline \multirow[t]{8}{*}{ Qualidade } & \multirow[t]{3}{*}{ Desempenho } & Rendimento de cozimento \\
\hline & & Ausência de odores durante e após o cozimento \\
\hline & & Arroz solto após o cozimento \\
\hline & \multirow[t]{3}{*}{ Estética } & Cor mais clara \\
\hline & & Cor mais uniforme \\
\hline & & Embalagem atrativa \\
\hline & ISO-9002 & Ter selo da ISO-9002 \\
\hline & Conformidade & Conformidade da qualidade apresentada \\
\hline Variedade & Variedade de produto & $\begin{array}{l}\text { Variedade de tipos de produtos, quanto a cor, peso, } \\
\text { composição, sabores e essências empregadas. }\end{array}$ \\
\hline \multirow[t]{5}{*}{ Imagem } & \multirow[t]{3}{*}{ A marca } & Valorização da marca no mercado \\
\hline & & Posicionamento ou liderança local de vendas \\
\hline & & Freqüência de propaganda \\
\hline & \multirow[t]{2}{*}{ A empresa } & Empresa conhecida e reconhecida no mercado \\
\hline & & $\begin{array}{l}\text { Confiabilidade no cumprimento de exigências } \\
\text { contratuais }\end{array}$ \\
\hline \multirow{7}{*}{$\begin{array}{r}\text { Desempenho de } \\
\text { entrega }\end{array}$} & \multirow{3}{*}{$\begin{array}{l}\text { Confiabilidade de } \\
\text { entrega }\end{array}$} & Entrega no dia combinado \\
\hline & & Garantia de entrega ao longo do ano \\
\hline & & Garantia de entrega ao preço cotado \\
\hline & $\begin{array}{l}\text { Velocidade de } \\
\text { entrega }\end{array}$ & Entrega mais rápida \\
\hline & $\begin{array}{l}\text { Flexibilidade de } \\
\text { volume }\end{array}$ & Vender qualquer quantidade \\
\hline & \multirow{2}{*}{$\begin{array}{l}\text { Flexibilidade de } \\
\text { entrega }\end{array}$} & Entregar em várias filiais \\
\hline & & Antecipar entregas \\
\hline \multirow[t]{8}{*}{ Assistência } & \multirow{3}{*}{$\begin{array}{l}\text { Atendimento do } \\
\text { representante }\end{array}$} & Amizade do representante \\
\hline & & Confiabilidade na data de visita do representante \\
\hline & & \begin{tabular}{|l|} 
Cortesia pessoal e profissional do representante \\
\end{tabular} \\
\hline & Pró-atividade & Atendimento personalizado \\
\hline & \multirow[t]{4}{*}{ Serviços agregados } & SAC - Canal acessível ao contato do cliente \\
\hline & & Serviço de atendimento pós-venda \\
\hline & & Repositores de estoque \\
\hline & & Promotores de venda \\
\hline
\end{tabular}

Fonte: Dias e Fensterseifer (2005)

A seguir, os respondentes foram apresentados ao AHP. Com mediação de pesquisador, os respondentes ordenaram e compararam os critérios, segundo suas preferências estratégicas. As respostas alimentaram uma planilha, construída por um dos pesquisadores, cujo vetor de resultados foi usado como distribuição de importância relativa para os fatores estratégicos pesquisados. A construção da planilha segue o método numérico de cálculo do autovetor de máximo autovalor exposto em Saaty (1991). Todas as CR (foram sete por empresa, totalizando 
quarenta e duas) ficaram abaixo de $6 \%$, portanto considera-se que os resultados podem ser atribuídos a processos racionais de decisão.

\subsection{Resultados}

A primeira empresa estudada foi a rede de supermercados Giassi. Os dados são apresentados na Tabela 2. Nas primeira e segunda colunas, têm-se os campos de competição e seus pesos. Nas terceira e quarta colunas, têm-se os critérios de competição e seus pesos relativos. Nas quinta e sexta colunas, têm-se os pesos finais, as importâncias relativas dos critérios de competição, obtidas pela multiplicação da segunda coluna pela quarta, e a ordem de importância dos critérios. Por exemplo, para esta empresa, os três critérios de competição mais importantes são ausência de odores, preço e conformidade da qualidade. A Equação 3 representa uma combinação linear entre os campos de competição e pode ser uma função-objetivo em um problema de otimização, caso haja planos de produção que visem a atingir objetivos em mais de um campo e sujeitos a restrições de recursos. De modo homólogo, as Tabelas de 3 a 7 e as Equações de 4 a 8 apresentam os resultados das entrevistas com os estrategistas dos supermercados Angeloni, WalMart - SC, Wal-Mart - RS, Zaffari e Unidasul, respectivamente. 
Tabela 2 - Estrutura ponderada de preferências dos estrategistas dos supermercados Giassi

\begin{tabular}{|c|c|c|c|c|}
\hline $\begin{array}{l}\text { Campos de } \\
\text { competição }\end{array}$ & Critérios competitivos & & $\begin{array}{l}\text { Importância } \\
\text { \% do critério }\end{array}$ & $\begin{array}{c}\text { Ordem de } \\
\text { importânci } \\
a\end{array}$ \\
\hline \multirow[t]{3}{*}{ Preço $24,3 \%$} & Preço & $63,7 \%$ & $15,5 \%$ & 2 \\
\hline & Regularidade & $25,8 \%$ & $6,3 \%$ & 5 \\
\hline & Prazo & $10,5 \%$ & $2,5 \%$ & 13 \\
\hline \multirow[t]{8}{*}{ Qualidade $44,2 \%$} & Rendimento de cozimento & $9,0 \%$ & $4,0 \%$ & 8 \\
\hline & Ausência de odores & $35,1 \%$ & $15,5 \%$ & 1 \\
\hline & Arroz solto & $7,5 \%$ & $3,3 \%$ & 10 \\
\hline & Cor mais clara & $6,2 \%$ & $2,7 \%$ & 11 \\
\hline & Uniformidade da cor & $15,3 \%$ & $6,8 \%$ & 4 \\
\hline & Embalagem atrativa & $3,0 \%$ & $1,3 \%$ & 19 \\
\hline & Iso 9002 & $2,6 \%$ & $1,2 \%$ & 20 \\
\hline & Conformidade & $21,2 \%$ & $9,4 \%$ & 3 \\
\hline Variedade $3,6 \%$ & & & $3,6 \%$ & 9 \\
\hline \multirow[t]{5}{*}{ Imagem $11,0 \%$} & Marca & $23,2 \%$ & $2,5 \%$ & 14 \\
\hline & Liderança em vendas & $46,5 \%$ & $5,1 \%$ & 6 \\
\hline & Freqüência de propaganda & $8,5 \%$ & $0,9 \%$ & 22 \\
\hline & Empresa reconhecida & $4,2 \%$ & $0,5 \%$ & 27 \\
\hline & Confiabilidade & $17,6 \%$ & $1,9 \%$ & 16 \\
\hline \multirow[t]{7}{*}{ Entrega $9,9 \%$} & Entrega no dia combinado & $14,6 \%$ & $1,4 \%$ & 18 \\
\hline & $\begin{array}{l}\text { Garantia de entrega ao longo do } \\
\text { ano }\end{array}$ & $11,0 \%$ & $1,1 \%$ & 21 \\
\hline & $\begin{array}{l}\text { Garantia de entrega ao preço } \\
\text { cotado }\end{array}$ & $40,6 \%$ & $4,0 \%$ & 7 \\
\hline & Entrega mais rápida & $6,3 \%$ & $0,6 \%$ & 25 \\
\hline & Vender qualquer quantidade & $3,6 \%$ & $0,4 \%$ & 28 \\
\hline & Entregar em várias filiais & $21,6 \%$ & $2,1 \%$ & 15 \\
\hline & Antecipar entregas & $2,3 \%$ & $0,2 \%$ & 31 \\
\hline \multirow[t]{8}{*}{ Assistência $7,1 \%$} & Amizade do representante & $2,2 \%$ & $0,2 \%$ & 32 \\
\hline & Confiabilidade da visita & $11,0 \%$ & $0,8 \%$ & 23 \\
\hline & Cortesia do representante & $4,3 \%$ & $0,3 \%$ & 29 \\
\hline & Atendimento personalizado & $37,6 \%$ & $2,7 \%$ & 12 \\
\hline & $\begin{array}{l}\text { Canal acessível ao contato do } \\
\text { cliente }\end{array}$ & $6,8 \%$ & $0,5 \%$ & 26 \\
\hline & $\begin{array}{l}\text { Serviço de atendimento pós- } \\
\text { venda }\end{array}$ & $11,0 \%$ & $0,8 \%$ & 23 \\
\hline & Repositores de estoque & $23,1 \%$ & $1,6 \%$ & 17 \\
\hline & Promotores de venda & $4,0 \%$ & $\begin{array}{c}0,3 \% \\
100,0 \%\end{array}$ & 30 \\
\hline
\end{tabular}

Competição $=0,243$. preço $+0,442$.qualidade $+0,036 \cdot$ variedade $+0,11$. imagem + 0,099.entrega $+0,071$.assistência (equação 3) 
Tabela 3 - Estrutura ponderada de preferências dos estrategistas dos supermercados Angeloni

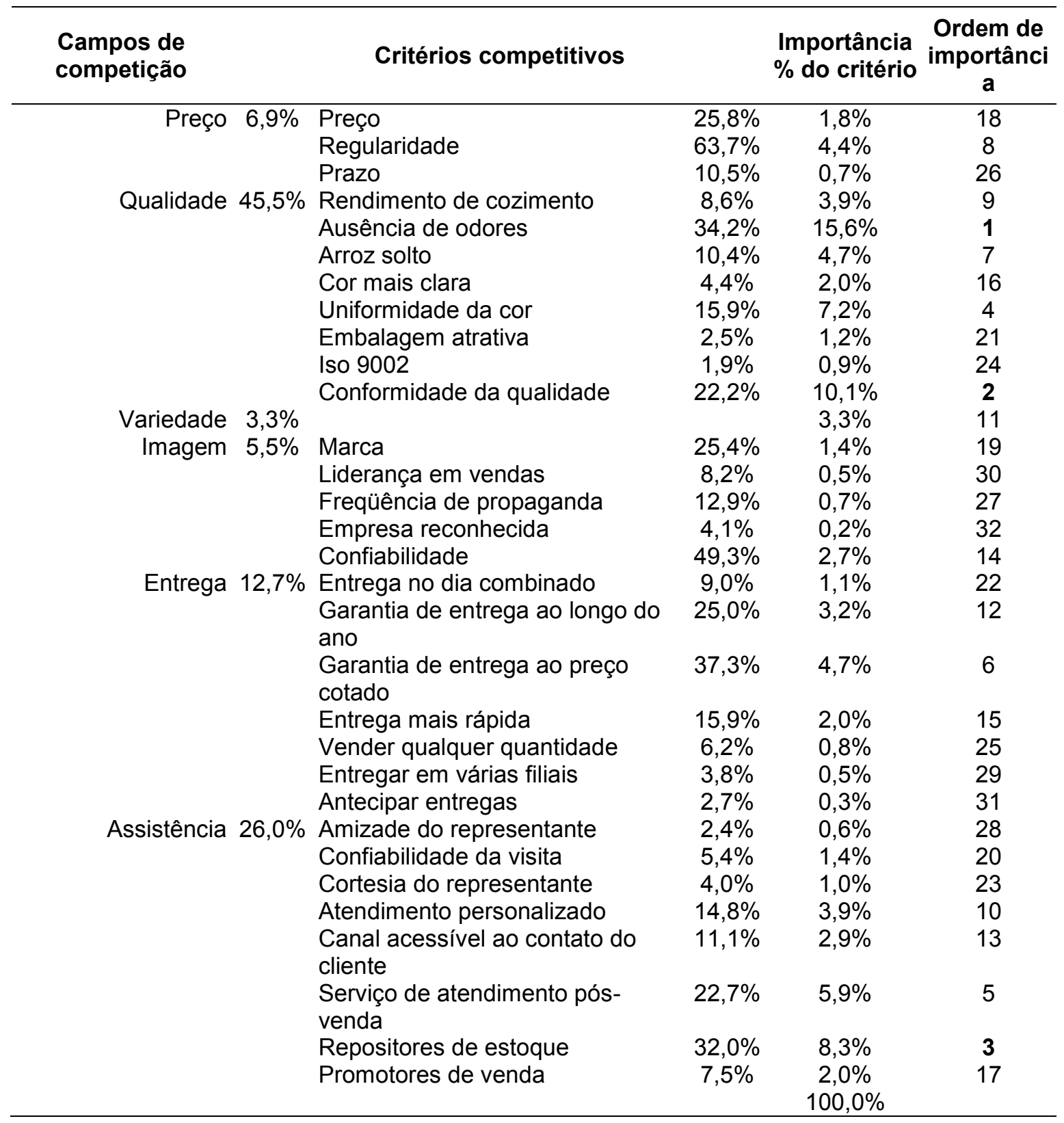

Competição $=0,069$. preço $+0,455$.qualidade $+0,033$.variedade $+0,055$.imagem + 0,127 .entrega $+0,26$.assistência (equação 4) 
Tabela 4 - Estrutura ponderada de preferências dos estrategistas dos supermercados Wal-Mart - SC

\begin{tabular}{|c|c|c|c|c|c|}
\hline $\begin{array}{l}\text { Campos de } \\
\text { competição }\end{array}$ & \multicolumn{3}{|c|}{ Critérios competitivos } & $\begin{array}{l}\text { Importância } \\
\text { \% do critério }\end{array}$ & $\begin{array}{c}\text { Ordem de } \\
\text { importânci } \\
\text { a }\end{array}$ \\
\hline \multirow{3}{*}{\multicolumn{2}{|c|}{ Preço $26,7 \%$}} & Preço & $63,7 \%$ & $17,0 \%$ & 1 \\
\hline & & Regularidade & $25,8 \%$ & $6,9 \%$ & 5 \\
\hline & & Prazo & $10,5 \%$ & $2,8 \%$ & 8 \\
\hline \multirow[t]{8}{*}{ Qualidade } & $39,2 \%$ & Rendimento de cozimento & $15,4 \%$ & $6,0 \%$ & 6 \\
\hline & & Ausência de odores & $22,6 \%$ & $8,9 \%$ & 4 \\
\hline & & Arroz solto & $36,1 \%$ & $14,2 \%$ & 3 \\
\hline & & Cor mais clara & $6,7 \%$ & $2,6 \%$ & 10 \\
\hline & & Uniformidade da cor & $4,5 \%$ & $1,7 \%$ & 13 \\
\hline & & Embalagem atrativa & $2,1 \%$ & $0,8 \%$ & 20 \\
\hline & & Iso 9002 & $2,9 \%$ & $1,1 \%$ & 17 \\
\hline & & Conformidade da qualidade & $9,9 \%$ & $3,9 \%$ & 7 \\
\hline \multirow{6}{*}{$\begin{array}{r}\text { Variedade } \\
\text { Imagem }\end{array}$} & $15,7 \%$ & & & $15,7 \%$ & 2 \\
\hline & $3,3 \%$ & Marca & $25,6 \%$ & $0,8 \%$ & 19 \\
\hline & & Liderança em vendas & $16,2 \%$ & $0,5 \%$ & 25 \\
\hline & & Freqüência de propaganda & $4,1 \%$ & $0,1 \%$ & 32 \\
\hline & & Empresa reconhecida & $8,3 \%$ & $0,3 \%$ & 28 \\
\hline & & Confiabilidade & $45,8 \%$ & $1,5 \%$ & 15 \\
\hline \multirow{7}{*}{ Entrega } & $6,9 \%$ & Entrega no dia combinado & $37,7 \%$ & $2,6 \%$ & 11 \\
\hline & & $\begin{array}{l}\text { Garantia de entrega ao longo do } \\
\text { ano }\end{array}$ & $16,0 \%$ & $1,1 \%$ & 18 \\
\hline & & $\begin{array}{l}\text { Garantia de entrega ao preço } \\
\text { cotado }\end{array}$ & $22,2 \%$ & $1,5 \%$ & 14 \\
\hline & & Entrega mais rápida & $11,1 \%$ & $0,8 \%$ & 21 \\
\hline & & Vender qualquer quantidade & $2,8 \%$ & $0,2 \%$ & 30 \\
\hline & & Entregar em várias filiais & $6,1 \%$ & $0,4 \%$ & 26 \\
\hline & & Antecipar entregas & $4,1 \%$ & $0,3 \%$ & 27 \\
\hline \multirow[t]{8}{*}{ Assistência } & $8,2 \%$ & Amizade do representante & $2,2 \%$ & $0,2 \%$ & 31 \\
\hline & & Confiabilidade da visita & $7,5 \%$ & $0,6 \%$ & 22 \\
\hline & & Cortesia do representante & $3,0 \%$ & $0,2 \%$ & 29 \\
\hline & & Atendimento personalizado & $6,6 \%$ & $0,5 \%$ & 24 \\
\hline & & $\begin{array}{l}\text { Canal acessível ao contato do } \\
\text { cliente }\end{array}$ & $14,6 \%$ & $1,2 \%$ & 16 \\
\hline & & $\begin{array}{l}\text { Serviço de atendimento pós- } \\
\text { venda }\end{array}$ & $7,1 \%$ & $0,6 \%$ & 23 \\
\hline & & Repositores de estoque & $31,8 \%$ & $2,6 \%$ & 9 \\
\hline & & Promotores de venda & $27,3 \%$ & $\begin{array}{c}2,2 \% \\
100,0 \%\end{array}$ & 12 \\
\hline
\end{tabular}

Competição $=0,267$. preço $+0,392$.qualidade $+0,157$ variedade $+0,033$.imagem + 0,069. entrega $+0,082$.assistência (equação 5) 
Tabela 5 - Estrutura ponderada de preferências dos estrategistas dos supermercados Wal-Mart - RS

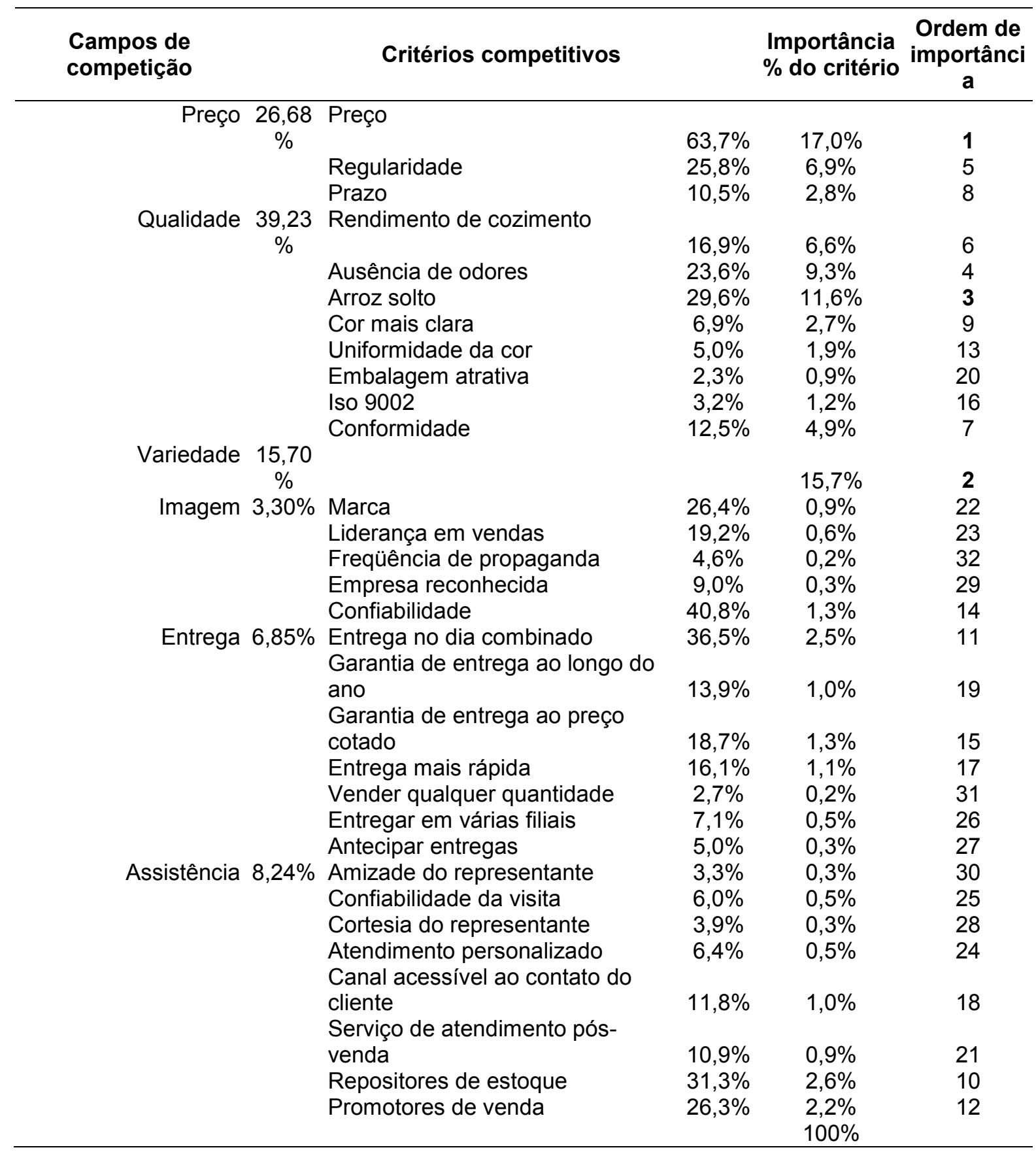

Competição $=0,267$. reço $+0,392$.qualidade $+0,157$ variedade $+0,033$.imagem + 0,068.entrega $+0,082$.assistência (equação 6) 
Tabela 6 - Estrutura ponderada de preferências dos estrategistas dos supermercados Zaffari

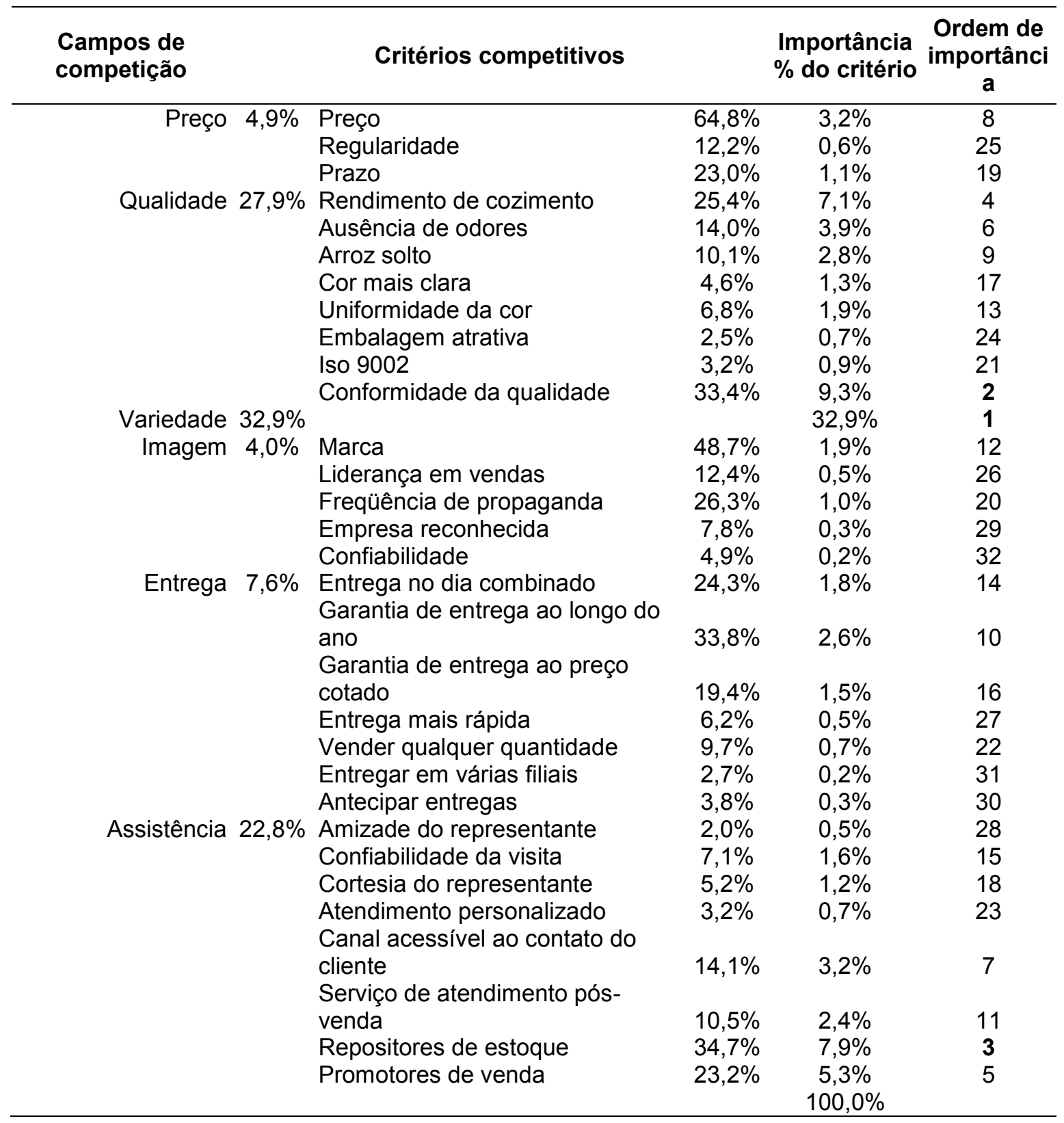

Competição $=0,049$. preço $+0,279$.qualidade $+0,329$.variedade $+0,04$.imagem + 0,076 .entrega $+0,23$.assistência (equação 7) 
Tabela 7 - Estrutura ponderada de preferências dos estrategistas dos supermercados Unidasul

\begin{tabular}{|c|c|c|c|c|}
\hline $\begin{array}{l}\text { Campos de } \\
\text { competição }\end{array}$ & Critérios competitivos & & $\begin{array}{l}\text { Importância } \\
\text { \% do critério }\end{array}$ & $\begin{array}{c}\text { Ordem de } \\
\text { importânci } \\
\text { a }\end{array}$ \\
\hline \multirow[t]{3}{*}{ Preço $26,0 \%$} & Preço & $63,7 \%$ & $16,6 \%$ & 1 \\
\hline & Regularidade & $25,8 \%$ & $6,7 \%$ & 6 \\
\hline & Prazo & $10,5 \%$ & $2,7 \%$ & 9 \\
\hline \multirow{8}{*}{ Qualidade $44,0 \%$} & Rendimento de cozimento & $15,7 \%$ & $6,9 \%$ & 5 \\
\hline & Ausência de odores & $12,1 \%$ & $5,3 \%$ & 7 \\
\hline & Arroz solto & $20,9 \%$ & $9,2 \%$ & 4 \\
\hline & Cor mais clara & $4,6 \%$ & $2,0 \%$ & 11 \\
\hline & Uniformidade da cor & $6,8 \%$ & $3,0 \%$ & 8 \\
\hline & Embalagem atrativa & $3,1 \%$ & $1,4 \%$ & 14 \\
\hline & Iso 9002 & $2,2 \%$ & $0,9 \%$ & 18 \\
\hline & Conformidade da qualidade & $34,6 \%$ & $15,2 \%$ & 3 \\
\hline \multirow{6}{*}{$\begin{array}{cc}\text { Variedade } & 15,6 \% \\
\text { Imagem } & 3,0 \%\end{array}$} & & & $15,6 \%$ & 2 \\
\hline & Marca & $44,2 \%$ & $1,3 \%$ & 15 \\
\hline & Liderança em vendas & $15,2 \%$ & $0,4 \%$ & 24 \\
\hline & Freqüência de propaganda & $26,0 \%$ & $0,8 \%$ & 19 \\
\hline & Empresa reconhecida & $9,7 \%$ & $0,3 \%$ & 27 \\
\hline & Confiabilidade & $4,9 \%$ & $0,1 \%$ & 31 \\
\hline \multirow[t]{7}{*}{ Entrega $6,9 \%$} & $\begin{array}{l}\text { Entrega no dia combinado } \\
\text { Garantia de entrega ao longo do }\end{array}$ & $23,7 \%$ & $1,6 \%$ & 12 \\
\hline & $\begin{array}{l}\text { ano } \\
\text { Garantia de entrega ao preço }\end{array}$ & $35,1 \%$ & $2,4 \%$ & 10 \\
\hline & cotado & $16,6 \%$ & $1,1 \%$ & 16 \\
\hline & Entrega mais rápida & $10,5 \%$ & $0,7 \%$ & 20 \\
\hline & Vender qualquer quantidade & $7,0 \%$ & $0,5 \%$ & 23 \\
\hline & Entregar em várias filiais & $4,2 \%$ & $0,3 \%$ & 26 \\
\hline & Antecipar entregas & $2,8 \%$ & $0,2 \%$ & 29 \\
\hline \multirow[t]{8}{*}{ Assistência $4,6 \%$} & Amizade do representante & $14,8 \%$ & $0,7 \%$ & 21 \\
\hline & Confiabilidade da visita & $33,4 \%$ & $1,5 \%$ & 13 \\
\hline & Cortesia do representante & $5,1 \%$ & $0,2 \%$ & 28 \\
\hline & Atendimento personalizado & $22,7 \%$ & $1,0 \%$ & 17 \\
\hline & $\begin{array}{l}\text { Canal acessível ao contato do } \\
\text { cliente } \\
\text { Servico de atendimento pós- }\end{array}$ & $10,9 \%$ & $0,5 \%$ & 22 \\
\hline & $\begin{array}{l}\text { Serviço de atendimento pos- } \\
\text { venda }\end{array}$ & $7,4 \%$ & $0,3 \%$ & 25 \\
\hline & Repositores de estoque & $3,5 \%$ & $0,2 \%$ & 30 \\
\hline & Promotores de venda & $2,2 \%$ & $\begin{array}{c}0,1 \% \\
100,0 \%\end{array}$ & 32 \\
\hline
\end{tabular}

Competição $=0,26$. preço $+0,44$.qualidade $+0,156$.variedade $+0,03$.imagem + 0,069.entrega + 0,046.assistência (equação 8)

\section{DISCUSSÃO}

Foram discutidos os resultados das aplicações e possíveis implicações do uso do modelo em estratégia de operações. Iniciou-se pelos resultados. A Tabela 8 apresenta as prioridades dadas pelas seis empresas aos campos de competição. A 
tabela informa a importância percentual e o posto que o campo ocupa na distribuição.

Tabela 8 - Distribuição de importâncias entre os campos de competição

\begin{tabular}{rcccccccccccc}
\hline & \multicolumn{3}{c}{ Preço } & \multicolumn{2}{c}{ Qualidade } & Variedade & \multicolumn{2}{c}{ Entrega } & \multicolumn{2}{c}{ Imagem } & \multicolumn{2}{c}{ Assistência } \\
\cline { 2 - 13 } Giassi-SC & $24,3 \%$ & $2^{\circ}$ & $44,2 \%$ & $1^{\circ}$ & $3,6 \%$ & $6^{\circ}$ & $11,0 \%$ & $3^{\circ}$ & $9,9 \%$ & $4^{\circ}$ & $7,1 \%$ & $5^{\circ}$ \\
Angeloni-SC & $6,9 \%$ & $4^{\circ}$ & $45,5 \%$ & $1^{\circ}$ & $3,3 \%$ & $6^{\circ}$ & $5,5 \%$ & $5^{\circ}$ & $12,7 \%$ & $3^{\circ}$ & $26,0 \%$ & $2^{\circ}$ \\
Wal-Mart-SC & $26,7 \%$ & $2^{\circ}$ & $39,2 \%$ & $1^{\circ}$ & $15,7 \%$ & $3^{\circ}$ & $3,30 \%$ & $6^{\circ}$ & $6,85 \%$ & $5^{\circ}$ & $8,24 \%$ & $4^{\circ}$ \\
Wal-Mart-RS & $26,7 \%$ & $2^{\circ}$ & $39,2 \%$ & $1^{\circ}$ & $15,7 \%$ & $3^{\circ}$ & $3,3 \%$ & $5^{\circ}$ & $6,9 \%$ & $6^{\circ}$ & $8,2 \%$ & $4^{\circ}$ \\
Zaffari-RS & $4,9 \%$ & $5^{\circ}$ & $27,9 \%$ & $2^{\circ}$ & $32,9 \%$ & $1^{\circ}$ & $4,0 \%$ & $4^{\circ}$ & $7,6 \%$ & $6^{\circ}$ & $22,8 \%$ & $3^{\circ}$ \\
Unidasul-RS & $26,0 \%$ & $2^{\circ}$ & $44,0 \%$ & $1^{\circ}$ & $15,6 \%$ & $3^{\circ}$ & $3,0 \%$ & $4^{\circ}$ & $6,9 \%$ & $6^{\circ}$ & $4,6 \%$ & $5^{\circ}$ \\
\hline
\end{tabular}

O campo de competição por qualidade teve a maior importância entre cinco das seis empresas. As três empresas de SC e duas do RS priorizaram a qualidade do arroz comprado. O campo de competição por preço foi o segundo mais importante pata três empresas, o quarto para duas e o quinto para uma. Sob a ótica de Hill (1994), talvez o critério preço seja do tipo qualificador e o critério qualidade seja do tipo ganhador de pedido. O campo de competição por variedade foi apontado como primeiro por uma empresa e em terceiro e sexto pelas demais. Após, vieram a competição por assistência, entre segundo e quinto posto, competição por imagem e por entrega, indicados pelas empresas entre terceiro a sexto postos.

As preferências formaram estruturas racionais, com CR menores do que $6 \%$. Com isto, julgou-se válido discutir os resultados com os estrategistas, mesmo que não tenha sido objetivo inicial de pesquisa investigar as causas das escolhas.

Ao descartar o preço baixo como principal campo de competição, as empresas pesquisadas entenderam que os clientes têm poder aquisitivo suficiente para decidir a compra não só pelo preço, mas também pela qualidade do produto. $A$ única empresa que não a considerou a qualidade como o principal campo de competição foi Zaffari, que escolheu o campo variedade. A escolha é coerente com a imagem que a empresa procura criar em sua publicidade institucional e ações de mercadologia, voltadas a público exigente e que se interessa por produtos diferenciados, não necessariamente baratos e muito menos padronizados, segundo 
seus estrategistas. Produtos baratos remeteriam a discussão para o campo custo e produtos padronizados para o campo qualidade.

Giassi e Angeloni pouco priorizaram a variedade, entendendo que 0 comprador final de arroz pouco pode ser estimulado por diferenciação do produto. Quanto à competição por assistência, Angeloni a coloca em segundo e Zaffari em terceiro posto. Angeloni teme problemas com fornecedores e Zaffari, por sua política de oferta de produtos inéditos, depende mais deste campo do que os outros concorrentes. A baixa prioridade de entrega pode estar ligada à eficiência das cadeias logísticas, ao alto nível de serviço e às políticas de estoque, que têm prevenido rupturas. Por fim, imagem ocupa o último lugar, o que pode ser explicado pelo esforço das empresas em reforçar as imagens dos supermercados, não das marcas dos produtos.

A análise foi estendida à segunda camada, incluindo os campos mais importantes: qualidade, preço e assistência. Por não haver ramificações em segunda camada, variedade não pode ser analisada. Os campos somam $86,5 \%$ de importância. Os demais campos são menos relevantes na competição. A Tabela 9 traz as prioridades atribuídas pelas empresas aos critérios que formam o campo de competição por qualidade.

Tabela 9 - Prioridades nos campos de competição por qualidade

\begin{tabular}{|c|c|c|c|c|c|c|c|c|}
\hline & $\begin{array}{l}\text { Rendi- } \\
\text { mento }\end{array}$ & Odores & $\begin{array}{l}\text { Arroz } \\
\text { solto }\end{array}$ & $\begin{array}{l}\text { Cor } \\
\text { clara }\end{array}$ & $\begin{array}{c}\text { Cor } \\
\text { uniforme }\end{array}$ & $\begin{array}{c}\text { Embala- } \\
\text { gem }\end{array}$ & Iso 9002 & $\begin{array}{l}\text { Conformi- } \\
\text { dade }\end{array}$ \\
\hline Giassi & $4^{a}$ & $1^{a}$ & $5^{a}$ & $6^{a}$ & $3^{a}$ & $7^{a}$ & $8^{a}$ & $2^{a}$ \\
\hline Angeloni & $5^{a}$ & $1^{a}$ & $4^{a}$ & $6^{a}$ & $3^{a}$ & $7^{a}$ & $8^{a}$ & $2^{a}$ \\
\hline $\begin{array}{r}\text { Wal-Mart } \\
\text { SC }\end{array}$ & $3^{a}$ & $2^{a}$ & $1^{a}$ & $5^{a}$ & $6^{a}$ & $8^{a}$ & $7^{a}$ & $4^{a}$ \\
\hline $\begin{array}{r}\text { Wal-Mart } \\
\text { RS }\end{array}$ & $3^{\circ}$ & $2^{\circ}$ & $1^{\circ}$ & $5^{\circ}$ & $6^{\circ}$ & $8^{\circ}$ & $7^{\circ}$ & $4^{\circ}$ \\
\hline Zaffari & $2^{\circ}$ & $3^{\circ}$ & $4^{\circ}$ & $6^{\circ}$ & $5^{\circ}$ & $8^{\circ}$ & $7^{\circ}$ & $1^{\circ}$ \\
\hline Unidasul & $3^{\circ}$ & $4^{\circ}$ & $2^{\circ}$ & $6^{\circ}$ & $5^{\circ}$ & $7^{\circ}$ & $8^{\circ}$ & $1^{\circ}$ \\
\hline
\end{tabular}

Giassi e Angeloni consideraram como principal prioridade a ausência de odores, Wal-Mart - SC e Wal-Mart RS arroz solto e Zaffari e Unidasul a conformidade de qualidade. Arroz solto e conformidade da qualidade ficaram duas vezes no segundo posto. Na outra ponta do continuum, todas consideram como as duas últimas prioridades embalagem atrativa e a a certificação ISO-9002. Esta 
última merece consideração, haja vista que os estrategistas das seis empresas não reconhecem a certificação como capaz de estimular o comprador de arroz em uma competição por qualidade, apesar de estar presente em outras indústrias. Os demais critérios oscilaram em posições intermediárias.

A Tabela 10 traz as ordens de prioridades atribuídas pelas empresas aos critérios de competição que formam o campo de competição por preço.

\begin{tabular}{rccc}
\multicolumn{4}{c}{ Tabela 10 - Prioridades nos campos de competição por preço } \\
\hline & Preço & Regularidade & Prazo \\
\hline Giassi & $1^{\mathrm{a}}$ & $2^{\mathrm{a}}$ & $3^{\mathrm{a}}$ \\
Angeloni & $2^{\mathrm{a}}$ & $1^{\mathrm{a}}$ & $3^{\mathrm{a}}$ \\
Wal-Mart SC & $1^{\mathrm{a}}$ & $2^{\mathrm{a}}$ & $3^{\mathrm{a}}$ \\
Wal-Mart SC & $1^{\mathrm{a}}$ & $2^{\mathrm{a}}$ & $3^{\mathrm{a}}$ \\
Zaffari & $1^{\mathrm{a}}$ & $3^{\mathrm{a}}$ & $2^{\mathrm{a}}$ \\
Unidasul & $1^{\mathrm{a}}$ & $2^{\mathrm{a}}$ & $3^{\mathrm{a}}$ \\
\hline
\end{tabular}

Como anteriormente, não foi objetivo de pesquisa investigar as causas das preferências, mas os resultados foram discutidos e deram margem a considerações. Para cinco empresas, o preço propriamente dito, ou seja, o valor a ser pago, independentemente das condições de pagamento, é o critério mais importante quando a competição se dá por preço. Também para cinco delas, o critério menos importante é prazo, por terem situação de caixa favorável no momento da pesquisa. Apenas uma considerou que o mais importante é a regularidade do preço ao longo do tempo. Uma possível especulação é que, para esta empresa, talvez seja mais importante o fornecedor manter um posicionamento de preços ao longo do ano do que ter um posicionamento de preços menores numa determinada época e depois não conseguir manter essa mesma política no restante do período.

A Tabela 11 traz as ordens de prioridades atribuídas pelas empresas aos critérios de competição que formam o campo de competição por assistência. 
Tabela 11 - Prioridades nos campos de competição por assistência

\begin{tabular}{|c|c|c|c|c|c|c|c|c|}
\hline & Amizade & $\begin{array}{l}\text { Confiabi- } \\
\text { lidade }\end{array}$ & Cortesia & $\begin{array}{l}\text { Atendi- } \\
\text { mento }\end{array}$ & Canal & $\begin{array}{l}\text { Pós- } \\
\text { venda }\end{array}$ & $\begin{array}{c}\text { Repositor } \\
\text { es }\end{array}$ & Promotores \\
\hline Giassi & $8^{\circ}$ & $3^{\circ}$ & $6^{\circ}$ & $1^{\circ}$ & $5^{\circ}$ & $3^{\circ}$ & $2^{\circ}$ & $7^{\circ}$ \\
\hline Angeloni & $8^{\circ}$ & $6^{\circ}$ & $7^{\circ}$ & $3^{\circ}$ & $4^{\circ}$ & $2^{\circ}$ & $1^{\circ}$ & $5^{\circ}$ \\
\hline $\begin{array}{r}\text { Wal-Mart } \\
\text { SC }\end{array}$ & $8^{\circ}$ & $4^{\circ}$ & $7^{\circ}$ & $6^{\circ}$ & $3^{\circ}$ & $5^{\circ}$ & $1^{\circ}$ & $2^{\circ}$ \\
\hline $\begin{array}{r}\text { Wal-Mart } \\
\text { RS }\end{array}$ & $8^{\circ}$ & $4^{\circ}$ & $7^{\circ}$ & $6^{\circ}$ & $3^{\circ}$ & $5^{\circ}$ & $1^{\circ}$ & $2^{\circ}$ \\
\hline Zaffari & $8^{\circ}$ & $5^{\circ}$ & $6^{\circ}$ & $7^{\circ}$ & $3^{\circ}$ & $4^{\circ}$ & $1^{\circ}$ & $2^{\circ}$ \\
\hline Unidasul & $3^{\circ}$ & $1^{\circ}$ & $6^{\circ}$ & $2^{\circ}$ & $4^{\circ}$ & $5^{\circ}$ & $7^{\circ}$ & $8^{\circ}$ \\
\hline
\end{tabular}

O critério repositores de venda ocupou o primeiro posto em quatro escolhas, e segundo e sétimo em uma escolha. Na atual estratégia de operação de supermercados, a tarefa de reposição é executada pelos distribuidores das mercadorias, o que justifica a importância atribuída por cinco das seis empresas. O canal acessível ao contato do cliente foi considerado o terceiro critério em importância por três empresas, quarto por duas e quinto por uma. Isso pode indicar a preocupação dos supermercadistas com os clientes no sentido de esses terem um canal de comunicação para expressar suas satisfações, descontentamentos e dúvidas com os produtos. A confiabilidade da visita do representante para a negociação foi considerada como primeiro, terceiro, quinto e sexto em importância para uma empresa e quarto para duas. A valorização desse critério competitivo indica que ainda é importante a negociação pessoal entre os compradores e fornecedores e pelo contato, ajustar as decisões de compra, principalmente devido às freqüentes oscilações de preços nessa cadeia produtiva. Na outra ponta, a cortesia no atendimento pessoal e profissional foi considerada como sexto e sétimo critério de competição em importância e amizade do representante foi considerado por cinco empresas como o menos importante e por uma como o terceiro mais importante. Isso indica a postura profissional que esses supermercadistas vêm adotando e exigindo dos fornecedores no processo de compras. O atendimento e serviços específicos e personalizados foram considerados como primeiro e segundo em importância por uma empresa. Para esses supermercadistas, o representante deve exercer um papel mais amplo do que o de vendedor; espera-se que esse interaja de forma mais pró-ativa, vislumbrando oportunidades de aprimoramento nas ações desenvolvidas, com vistas ao aumento da competitividade de ambas as 
organizações através de políticas ganha-ganha. Os demais critérios de competição ocuparam e se distribuíram por postos intermediários.

Os resultados e a discussão com os estrategistas apontaram que a função distribuição pode ser considerada de alta importância na formulação da estratégia de operação para venda de arroz em supermercados. Repositores de estoque e canal de comercialização, que foram escolhidos como os critérios de importância média mais alta, refletem o quanto a função distribuição pode interferir nos resultados da operação, segundo os estrategistas. Na outra ponta, os critérios mais ligados às relações pessoais, tais como amizade e cortesia do representante, foram considerados de pouca importância.

\subsection{Implicações em estratégia de operação}

O uso do método pode trazer benefícios na gestão de práticas estratégicas de empresas.

O uso de julgamento pareado produz prioridades relativas, não mais absolutas, valendo o que mencionou Saaty (2006): a estrutura de preferências tornase intrinsecamente dependente e pode variar se objetivos forem retirados ou acrescidos. Sellitto, Borchardt e Pereira (2006) apontam que a comparação pareada, em oposição à avaliação absoluta, fez decisores considerarem mais aspectos, tornou a discussão mais rica e requereu mais tempo para a explicitação do modelo mental dos decisores. Segundo os autores, o modo hierárquico de pensar pareceu ter ajudado a selecionar os fatores que influenciam no resultado, mais do que quando os fatores foram julgados isoladamente. Alguns decisores, em avaliação absoluta, deram prioridades altas a muitos objetivos, mas em avaliação relativa foram obrigados a ser seletivos, ou seja, enfocaram uma ou poucas prioridades. Em resumo, distribuição de importância foi, no caso relatado, mais seletiva do que atribuição de importância.

O uso do AHP produziu equações lineares que podem ser úteis caso seja preciso priorizar recursos produtivos. Em um plano de operação, os cursos de ação podem afetar vários campos de competição. Se houver escassez de recursos, não será possível executar todos os cursos ao mesmo tempo. Basta que se julgue qualitativamente (nenhum; pouco; medianamente; muito; totalmente) o impacto de 
cada curso em cada campo de competição (o quanto o curso afeta o preço, a qualidade, etc.) e se avalie o quanto cada curso exige dos recursos restritos. Dadas as restrições de recursos e a equação de competição da empresa, tem-se um problema de otimização binária: cada curso será ou não executado, formando uma combinação ótima de cursos de ação, dentro das restrições de recursos. Uma aplicação deste método em manufatura foi apresentada por Sellitto (2005).

Outro modo de usar o método ora proposto é integrá-lo com a matriz importância-desempenho (SLACK, 2002), indicado por Paiva et al. (2004) e por Carvalho e Laurindo (2007) para uso em estratégia de operações. Para tanto, além das importâncias atribuídas aos critérios de competição, é necessária avaliação de desempenho da operação nestes mesmos critérios, o que não foi feito neste artigo. Remete-se esta avaliação à continuidade de pesquisa.

O método de Slack (2002) exige: (i) definição de objetivos de manufatura; (ii) avaliação do desempenho atual nestes objetivos; (iii) priorização segundo as lacunas [importância - desempenho]; e (iv) formulação de planos para superar as lacunas priorizadas. Inicia-se pela discussão das necessidades de clientes e dos potenciais próprios e de concorrentes, surgindo objetivos de atendimento. Atribuemse pesos aos objetivos, normalmente por escalas qualitativas de julgamento, do tipo: a presença deste objetivo, neste mercado, oferece uma vantagem [decisiva; ...; importante; ....; nula]. Associando valores numéricos à escala, chega-se à quantificação e ordenação de prioridades. Segue a avaliação do desempenho atual, por escala compatível. Se o objetivo tem mais importância do que o desempenho, um plano deve aumentar o desempenho da operação no objetivo. Se o objetivo tem menos importância do que o desempenho, recursos usados no objetivo podem ser deslocados para aumentar o desempenho em outro objetivo.

Dado que existe um conjunto de objetivos, se possível estruturado (neste artigo, a estrutura de objetivos é a do Quadro 1), o método ora proposto, acrescido de avaliação de desempenho, pode ser uma alternativa para partes do método descrito.

Os decisores devem responder a perguntas do tipo: [para atender o cliente] ou [para superar o concorrente] ou [para explorar este potencial], o objetivo $A$ é [melhor ou pior] do que o objetivo $B$. Dado que $A$ é melhor do que $B$, o grau de diferença é [mínimo; baixo, médio, alto; extremo]. Cada comparação exige um 
processo de discussão entre decisores, emergindo um modelo mental de crenças, compartilhado ou não pelos decisores. Caso não se chegue a uma solução consensual, que nem sempre é desejável, pode-se proceder a julgamentos individuais completos e extrair a média das ponderações, ou ainda extrair a média das comparações e obter uma única matriz de julgamentos. Não havendo consistência $(C R<10 \%)$, revisam-se os julgamentos que contribuíram para a inconsistência.

Para a avaliação do desempenho atual da operação, segundo os objetivos estratégicos, a pergunta que os decisores devem responder é: o desempenho atual da operação no objetivo $A$ é: [excelente $=1 ; \ldots$ médio $=0,5 ; \ldots$; péssimo $=0$ ]. desempenho no objetivo é o produto entre a importância relativa do objetivo e o desempenho, segundo a escala. Por exemplo, se a importância do objetivo $i$ é $l_{i}$ e o desempenho no objetivo é excelente, agregam-se $l_{i}$ pontos percentuais ao desempenho global. Se o desempenho no objetivo é médio, agregam-se $0,5 \times l_{i}$ ao desempenho global. Caso este não atinja a cem pontos percentuais, calculam-se e listam-se, por ordem de magnitude, as lacunas [importância - desempenho]. As lacunas mais positivas devem receber planos que usarão recursos que podem sair de planos que sustentam as lacunas menos positivas. Caso não haja recursos suficientes a realocar, ou esta não seja interessante, novos recursos deverão ser alocados, o que pode ser justificado pelo acréscimo de competitividade que pode ser esperado na operação.

Entende-se que o método ora apresentado, com objetivos estruturados para uma indústria, e não apenas para uma operação de uma empresa, se integrado a outros procedimentos estratégicos, tais como a formulação de planos e a medição de desempenho, pode apoiar a formulação de estratégias de produção e operações nesta indústria.

\section{CONCLUSÕES}

Este artigo apresentou um estudo de caso múltiplo, em seis redes de supermercados com operações em Santa Catarina e no Rio Grande do Sul. O objetivo foi mensurar a prioridade ou grau de importância que estas empresas conferem a critérios competitivos considerados na decisão de compra de arroz. Os 
critérios competitivos foram extraídos de uma estrutura de competição apresentada em Dias e Fensterseifer (2005). Uma limitação da pesquisa é que esta foi aplicada apenas em grandes redes dos dois estados. Outra limitação foi imposta pelo método do estudo de caso: o resultado vale para os casos, não para a indústria. No entanto, o método de trabalho empregado pode ser estendido a outras indústrias. A contribuição essencial da pesquisa foi o método de trabalho, replicável a outras indústrias, produtos e serviços, a formulação do problema e seis exemplos de aplicação. Os resultados dos seis casos podem ser modificados caso se use outro método.

Chegou-se, pela análise dos casos, a estruturas de competição ponderadas, uma para cada empresa, que priorizaram os campos e os critérios de competição. Como as amostras (seis empresas) não são representativas da indústria, não é válido estender conclusões para além das empresas. Peculiaridades estratégicas das empresas surgiram na ponderação dos critérios de competição. Tais peculiaridades também podem mudar ao longo do tempo, o que pode indicar que uma distribuição de importância relativa não seja duradoura. Deste modo, o método ora proposto pode ser usado na análise e formulação de uma estratégia de operação, mas deve ser aplicado a cada empresa especificamente e replicado periodicamente.

A pesquisa suscitou questões que podem ser exploradas na continuidade. Sugere-se a extensão do método a empresas de menor porte que vendam arroz e a outros produtos alimentícios, nas mesmas empresas. Outra aplicação que pode ser feita é a análise em conjunto ao longo da cadeia produtiva arrozeira. A aplicação seria repetida nas etapas de produção (granjas), na fabricação e embalamento e nas distribuidoras. Deste modo, seria possível determinar como as prioridades evoluem e se transformam ao longo da cadeia. Também sugere-se a inclusão de procedimento para avaliação do desempenho nos critérios competitivos priorizados.

\section{REFERÊNCIAS}

ABDI, M.; LABIB, A. A design strategy for reconfigurable manufacturing systems (RMSs) using analytical hierarchical process (AHP): a case study. International Journal of Production Research, v.41, n.10, p.2273-2299, 2003.

BERTOLINI, M.; BEVILACQUA, M. A combined goal programming-AHP approach 
to maintenance selection problem. Reliability Engineering \& System Safety, v.91, n.7, p.839-848, 2006.

BITITCI, U.; SUWIGNJO, P.; CARRIE, A. Strategy management through quantitative modelling of performance measurement systems. International Journal of Production Economics, v.69, n.1, p.15-22, 2001.

CARVALHO, M.; LAURINDO, F. Estratégia competitive: dos conceitos à implementação. São Paulo: Atlas, 2007.

CHIOU, H.; TZENG, G. Fuzzy multiple-criteria decision-making approach for industrial green engineering. Environmental Management, v.30, n.6, p.816-830, 2002.

CONTADOR, J. C. Campos da competição. Revista de Administração, São Paulo, v.30, n.1, p.32-45, jan./mar.1995.

CORBETT, C.; WASSENHOVE, L. Trade-Offs? Competence and competitiveness in manufacturing strategy. California Management Review, v.35, n.4, p.107-122, 1993.

DAVIS, M.; AQUILANO, N.; CHASE, R. Fundamentos da administração da produção. Poro Alegre: Bookman, 2001.

DIAS, M.; FENSTERSEIFER, J. Critérios competitivos de operações agroindustriais: um estudo de caso no setor arrozeiro. REAd, v.11, n.3, 2005.

DYER, J. Remarks on the Analytic Hierarchy Process. Management Science, v.36, n.3, p.249-258, 1990a.

DYER, J. A clarification of "Remarks on the Analytic Hierarchy Process".

Management Science, v.36, n.3, p.274-275, 1990 b.

EISENHARDT, K. Building theories from case study research. Academy of Management Review, v.14, n.4, p.532-550, 1989.

FINE, C.; HAX, A. Manufacturing strategy: a methodology and an illustration. Interfaces, v.15, n.6, p.28-46, 1985.

FORMAN, E.; SELLY, M. Decisions by objectives. Expert Choice, Inc. Disponível em: <http://www.expertchoice.com>. Acesso em: maio 2004.

GOMES, L; ARAYA, M.; CARIGNANO, C. Tomada de decisão em cenários complexos. São Paulo: Thomson Learning, 2004.

HARKER, P.; VARGAS, L. Reply "Remarks on the Analytic Hierarchy Process" by J. S. Dyer. Management science, v.36, n.3, p.269-273, 1990.

HILL, T. Manufacturing strategy: text and cases. Burr Ridge, IL: Irwin, 1994.

HOGARTH, R. Judgement and choice. Essex, UK :John Wiley \& Sons , 1988. 
KEENEY, R.; RAIFFA, H.: Decisions with multiples objectives: preferences and value trade-offs. New York: John Wiley and Sons , 1976.

KURTTILA, M.; MAUNO M.; KANGAS, J.; KAJANUS, M. Utilizing the analytic hierarchy process (AHP) in SWOT analysis - a hybrid method and its application to a forest-certification case. Forest Policy and Economics, v., n.1, p.41-52, 2000.

LIBERATORE, M. An Extension of the Analytic Hierarchy Process for Industrial R\&D project selection and resource allocation. IEEE Transactions on Engineering Management, v.34, n.1, p.12-18, 1987.

LIU, F.; HAI, H. The voting analytic hierarchy process method for selecting supplier. International Journal of Production Economics, v.97, p.308-317, 2005.

LU, M.; MADU, C.; KUEI, C.; WINOKUR, D. Integrating QFD, AHP and benchmarking in strategic marketing. Journal of Business \& Industrial Marketing, v.9, n.1, p.41-50, 1994.

MACHADO, E.; GOMES, L.; CHAUVEL, M. Avaliação de estratégias em marketing de serviços: um enfoque multicritério. Revista de Administração Mackenzie, v.4, n.2, p.61-85, 2003.

MASELLA, C.; RANGONE, A. A contingent approach to the design of vendor selection systems for different types of co-operative customer /supplier relationships, International Journal of Operations \& Production Management, v.20, n.1, p.70$84,2000$.

PAIVA, E.; CARVALHO JR., J.; FENSTERSEIFER, J. Estratégia de produção e de operações: conceitos, melhores práticas, visão de futuro. Porto Alegre: Bookman, 2004.

PARTOVI, F.; WHITERS, B.; BRADFORD, J. How tompkins rubber company used analytic hierarchy process to enhance ISO-9000 related decision making. Production and Inventory Management Journal, v.43, n.1/2, p.148-159, 2002.

PARTOVI, F.; BURTON, J.; BANERJEE, A. Application of Analytical Hierarchy Process in Operations Management. International Journal of Operations \& Production Management, v.10, n.3, p.5-19, 1993.

PLATTS, K., GREGORY, M. A manufacturing audit approach to strategy formulation. In: VOSS, C. (org.) Manufacturing Strategy, Process and Content. London: Chapman and Hall, p.29-55, 1992.

RANGONE, A. An analytical hierarchy process framework for comparing the overall performance of manufacturing departments. International Journal of Operations \& Production Management, v.16, n.8, p.104 -119, 1996.

ROESCH, S. Projetos de estágio e de pesquisa em administração: guia para estágios, trabalhos de conclusão, dissertações e estudos de caso. São Paulo: Atlas, 1999. 
SAATY, T. An exposition of the AHP in reply to the paper "remarks on the analytic hierarchy process". Management Science, v.36, n.3, p.259-267, 1990.

SAATY, T. Método de Análise Hierárquica. São Paulo: Makron Books, 1991.

SAATY, T. Rank from comparisons and from ratings in the analytic hierarchy/network processes. European Journal of Operational Research, v.168, p.557-570, 2006.

SALOMON, V. Auxílio à decisão para a adoção de políticas de compras, Produto \& Produção, v.6, n.1, p.1-9, 2002.

SELLITTO, M. Medição e controle de desempenho estratégico em sistemas de manufatura. 195 f. 2005. Tese (Doutorado em Engenharia de Produção). Escola de Engenharia, Universidade Federal do Rio Grande do Sul. Porto Alegre, 2005.

SELLITTO, M.; WALTER, C. Medição e pré-controle do desempenho de um plano de ações estratégicas em manufatura. Gestão \& Produção, v.12, n.3, p.443-458, 2005.

SELLITTO, M.; WALTER, C. Avaliação do desempenho de uma manufatura de equipamentos eletrônicos segundo critérios de competição. Produção, v.16, n.1, p.34-47, 2006.

SELLITTO, M.; MENDES, L. Avaliação comparativa de desempenho de três cadeias de suprimentos em manufatura. Produção, v.16, n.3, p552-568, 2006.

SELLITTO, M.; BORCHARDT, M.; PEREIRA, G. Avaliação multicriterial de desempenho: um estudo de caso na indústria de transporte coletivo de passageiros. Gestão \& Produção, v.13, n.2, p.339-352, 2006.

SKINNER, W. Manufacturing: missing link in corporate strategy. Harvard Business Review, Boston, v.47, n.3, p.136-145, 1969.

SLACK, N. Vantagem Competitiva em Manufatura. 2. ed. São Paulo: Atlas, 2002.

SUPERHIPER. São Paulo-SP: ABRAS, 2006, mensal.

WHEELWRIGHT, S. C. Manufacturing strategy: defining the missing link. Strategic Management Journal, v.5, n.1, p.77-91, 1984.

WIND, Y.; DOUGLAS, S. International portfolio analysis and strategy: the challenge of the 80 's. Journal of International Business Studies, v.12, n.2, p.69-82, 1981.

WIND, Y.; SAATY, T. Marketing applications of the analytic hierarchy process. Management Science, v.26, n.7, p.641-658, 1980.

YIN, R. Estudo de caso: planejamento e método. Porto Alegre: Bookman, 2001. 


\section{(C) $(0)$}

Artigo recebido em 27/04/2010 e aceito para publicação em 25/08/2010. 